\title{
The Impacts of Poor Solid Waste Management in Legetafo-Legedadi Town, Oromia, Ethiopia
}

\author{
Mesfin Assefa ${ }^{*}$, Birhanu Girma \\ Ethiopia Institute of Architecture, Building Construction and City Development, Addis Ababa University, Addis Ababa, Ethiopia \\ Email address: \\ Mesfinassefa491@gmail.com (M. Assefa) \\ ${ }^{*}$ Corresponding author \\ To cite this article: \\ Mesfin Assefa, Birhanu Girma. The Impacts of Poor Solid Waste Management in Legetafo-Legedadi Town, Oromia, Ethiopia. Urban and \\ Regional Planning. Vol. 5, No. 2, 2020, pp. 61-69. doi: 10.11648/j.urp.20200502.14
}

Received: May 27, 2020; Accepted: June 15, 2020; Published: June 29, 2020

\begin{abstract}
Forced, by rapid increases in urban population, municipal administrations in Ethiopia are wrestling with an ever rising problem of solid waste management. In the emerging Legetafo-Legedadi town open and indiscriminate dumping of solid waste is rampant and piles of decaying growing in the garbage remain uncollected. The study focused on an analysis and discussion of the challenges of solid waste around the open dumpsite and environmental, economic, and health impacts arising from the haphazard and poor waste management. In doing investigation, descriptive research design was followed. Using purposive sampling technique, key informants were selected. Besides, participants were selected using simple random sampling technique. The data gathering instruments employed in the study were, interview, key informant interviews, focus group discussion, and site observation. The findings of the study revealed that existing solid waste collection practice could not cope with the increasing volume of solid waste in the town. Illegal dumping is increasing polluting the roadsides, open spaces, and temporary collection sites with potential health menace to the residents of the town Accordingly, 59 percent (216) of the respondents stated that open dumpsite posed public health risks; 18.9 percent (69) said that there was uncontrolled dumping even at the dumpsite, and 12.3 percent (45) argued that the open dumpsite contaminated groundwater. Apparently, the residents are facing health and environmental challenges due to poor management of solid wastes. With this regards, it is recommended that the town administration should apply integrated solid waste management system.
\end{abstract}

Keywords: Poor Waste Management, Integrated, Environmental, Economic, Climate Impact

\section{Introduction}

The problems caused by solid waste critically impacts planet earth. Poor waste management has multidimensional impacts on the environment, health, socio-economic and aesthetic value $[17,18]$. The problem is more acute in developing countries, where financial, human, and other critical resources are generally scarce. Although several publications dealt with a variety of topics in the field of solid waste management, most of these documents have been published to address the needs of industrialized nations. Only a few documents have been specifically written to provide information on the impacts of improper management of solid waste that is required by those in developing countries [17]. This study also aims to fill this gap in the literature.

\subsection{Problem of the Statement}

Today, the emerging town of Lege-TafoLegedadi of Oromia Region faces poor solid waste management that has become one of the most intractable environmental problems. One of the main problems facing the town is open and indiscriminate dumping of refuses. Piles of decaying garbage are found in strategic locations in the heart of the town. Wastes in such places are obviously a source of air and water pollution, land contamination and environmental degradation [13] Quite a few studies have looked at the problem of solid waste management at different Ethiopian cities/towns (e.g, Birhanu \& Berisa, 2015; Desta, Worku, \& Fetene, 2014; Erasu, Feye, Kiros, \& Balew, 2018; Gedefaw, 2015; Heyi, 2018; Lemma et al., 2019; Tyagi, Fantaw, \& Sharma, 2014; Woldetsadik, 2017). The most common thread in these 
studies is that the management of solid waste is generally very weak and suffers from poor solid waste management. One of the factors undermining the existing solid waste management system in the Laga-Tafo Lege Dadi Town is believed to be the absence of proper management of solid waste with ominous consequences for the health of residents who have to deal with growing health complications from the environmental pollution, which requires an investigation to look into the problem and come up with conclusions and recommendations.

\subsection{Basic Research Questions}

This study is intended to answer the following research questions:

1. What are the main effects of the poor solid waste management on the environment, health and the economy of the town?

2. How the impact of poor solid waste management does mitigate?

\subsection{Objectives of the Study}

\subsubsection{General Objective of the Study}

The general objective of the study is to explore the impact of poor the solid waste management system practiced in Legetafo-Legedadi town.

\subsubsection{Specific Objectives}

1. To investigate the effects of Legetafo-Legedadi town's solid waste management on the environment, health, and economy

2. To device practical solution to mitigate the impact of poor solid waste management in the town.

\subsection{Significance and Justification of the Study}

The study is particularly significant for the LegetafoLegedadi town Administration because it offers them a solution for effect of poor solid waste management through Integrated Solid Management System, which they can adopt as a planning and working document to overcome the growing problems faced by the town and its residents in costeffectively and sustainably managing solid waste. Although this study is about Legetafo-Legedadi town, the findings of this study is however not only relevant to Legetafo-Legedadi but also relevant to the many other towns and cities in the country dealing with the problem of solid waste management, which is bound to take more and more of their attentions as well as resources in the years and decades ahead. It can also serve as a guideline and reference for researchers and practitioners dealing with the problem of solid waste management. Since most of the analyses on the deleterious and multidimensional impacts of poor solid waste management [18] have been published to address the needs of industrialized nations, there is a dearth of information on the impacts of improper management of solid waste in developing countries [17], where the problem is acute. Even though this study is on the Town of Legetafo-Legedadi and its intention is not generalizations, its findings can help fill at least a small part of this gap in the literature.

\subsection{Scope of the Study}

The geographic scope of this study is limited to the town of Legetafo-Legedadi, Finfinne Special Zone, Oromia National Regional State. Even though managing solid waste requires a holistic and broad initiative and involves the participation of multiple actors and factors in its formulation, implementation, and evaluation phases, the scope of this study is limited to the effect of improper management of solid waste. While making a broader inquiry into the solid waste management is necessary, this is not attempted here due to time constraint and resource limitations. Hence, the scope of the research is limited to examining the impacts poor solid waste management and assessing whether the town of Legetafo-Legedadi exert its effort to mitigate effect of poorsolid waste management system in the town.

\subsection{Limitation of the Study}

It is clear that research works are not free of limitations. Similarly, this study has its own limitations. Chief among the limitations is the fact that respondents might have exaggerated or underestimated some of the questions presented to them for fear that the answers would affect their livelihoods.

The validity of data collected through the survey questionnaire assumed that respondents would answer the questions truthfully [7]. However, this assumption can be problematic because of a couple reasons. First and foremost, fear of what will happen pertinent to their response. Second, even though their answers will be kept confidential and the anonymity of respondents is assured, some could still be reluctant to express views critical of the municipality and its local government organs. However, this potential problem is mitigated by the mixed method nature of the study and the opportunity to triangulate findings from multiple data sources.

There is also another major mitigation factor. The fact that the participants of the study are responsible adults, other limitations could have also emanated from the inbuilt and unexpressed attitudes and perceptions of the participants of the study towards some variables.

Here again, the researchers attempted to minimize these limitations through triangulation employing different methods such as key informant interviews, focus group discussions, and field observations combining both quantitative and qualitative data. The limitation is also overcome by asking ordinary citizens the same questions enabling the researcher to crosscheck against responses from the officials and experts working for the town administration.

\section{Review of Relate Literature}

\subsection{Environmental Impacts}

Inappropriate management of solid waste hurts the environment in many ways. Poor solid waste management 
can provide a breeding ground for rodents and vector insects for which it provides food and shelter. On the other hand, the foul odors and unsightliness, which comes from unmanaged solid waste, make the environment less attractive for humans to enjoy and cherish. These impacts are not confined merely to solid waste disposal sites. In fact, they pervade the area surrounding the disposal sites and wherever the wastes are generated, spread, accumulated, or sites to which the waste is temporarily transferred [17]. Unless an organic waste is appropriately managed, its adverse impact will continue until it has fully decomposed or otherwise stabilized. Uncontrolled or poorly managed intermediate decomposition products can also contaminate the air, water, and soil resources.

Uncontrolled solid waste dumping exposes urban residents; to potential risks to pollute water, particularly those living adjacent to dumpsites, unhealthy food sources, air, land, and vegetation pollution. Poor solid waste disposal and handling of wastes leads to environmental degradation, ecosystem destruction, and high risks to public health. Such accumulations of solid wastes are health hazards not only to urban residents but also threaten the environment [17].

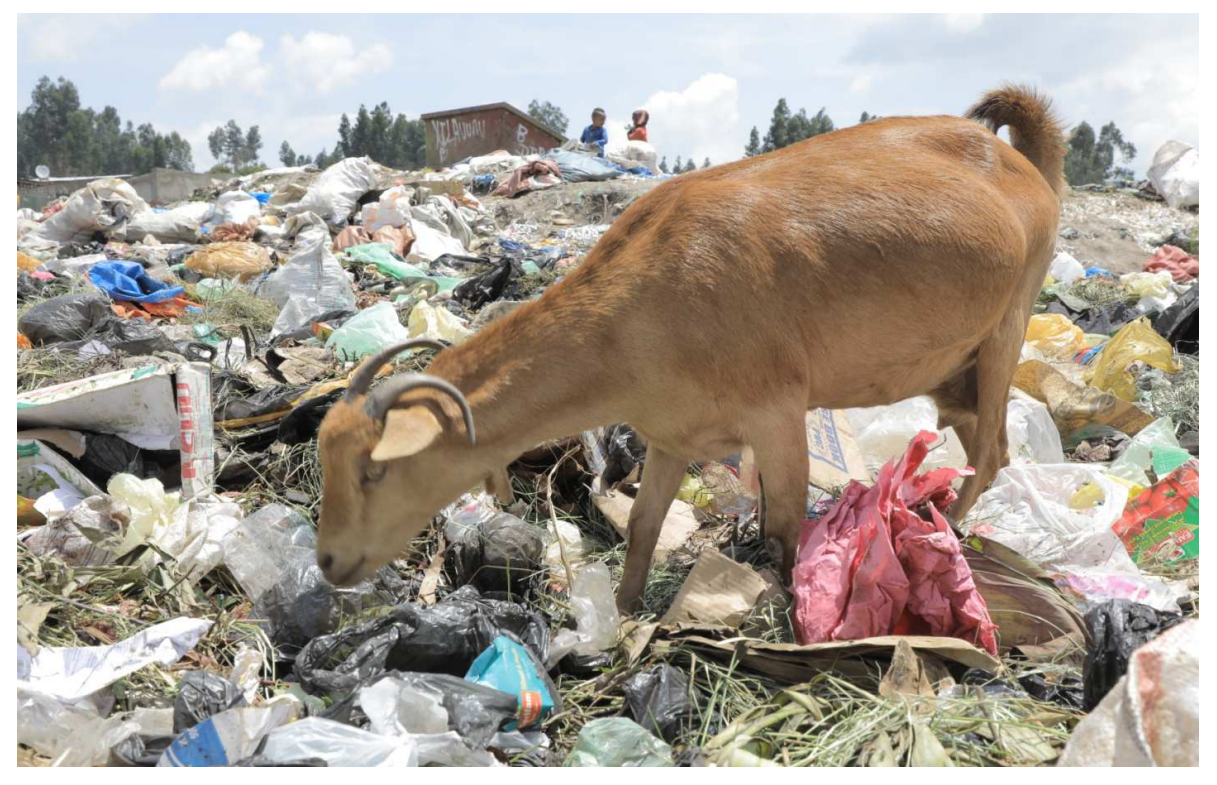

Source; Photo taken during field observation, 2019

Figure 1. Uncontrolled Solid waste disposal of the town.

\subsection{Climate Change Impact}

The importance of public health, environmental protection, and resource management are reinforced by the imperative to reduce carbon emissions in a move to a sustainable, carbon neutral, society. Municipal solid waste management and wastewater contribute about $3 \%$ to current global anthropogenic greenhouse gas emissions, about half of which is methane from anaerobic decomposition of organic waste in landfills and other waste disposal sites. One forecast suggests that, without mitigation, this could double by 2020 and quadruple by 2050 . It is ironic that these alarming increases are largely due to improved disposal in low and middleincome countries open dumps decompose partly aerobically, and so generate less methane than mostly anaerobic sanitary landfills. [18]

\subsection{Health and Social Impacts}

Unmanaged solid waste is causing many health complications. Studies have shown that a high percentage of workers who handle refuse, and individuals who live near or on disposal sites, are infected with gastrointestinal parasites, worms, and related organisms. Contamination of this kind is likely at all points where waste is handled. Although vector insects and rodents can certainly transmit various pathogenic agents (amoebic and bacillary dysenteries, typhoid fever, salmonellosis, and many others), it often is difficult to trace the sources of such scourges as the cholera, yellow fever, plague, and the various ailments caused by parasites to specific populations (UNEP, 2005).

One thing is not in dispute: That there is a significant increase in the incidence of sickness among children who live in households where garbage is dumped or burned in the yard. Uncollected solid waste clogs the drain and causes flooding and subsequent water-borne diseases. People living downwind of a burning dumpsite will likely suffer from respiratory diseases. Contaminated liquids or leachate, leaking from dumpsite could pollute the city's drinking water supplies. Waste dumps potentially serve as a breeding ground for Malaria, thus having negative implications in achieving Millennium Development Goals (MDGs) [18].

The social impacts created by MSW include the unpleasant odour when garbage is left uncollected and the unpleasant odour one suffers due to proximity to a landfill site, dirty surroundings, breeding of mosquito, worms, insects and flies due to the landfill site and the uncollected garbage and the release of smoke and poisonous gases giving rise to safety problems. These impacts are also referred to as dis-amenities due to MSW [5]. 


\subsection{Economic Impacts}

In some developing countries, municipalities spend a disproportionate amount of their meager financial resources on certain solid waste services, in particular, waste collection and sweeping. In the past, a common approach to curing poor service provision was to simply expend more capital to acquire additional equipment, make new design, and construct new facilities. The problem is that even after spending a considerable amount of resources on such efforts, rarely are these efforts sufficient and effective in addressing and remedying inefficiencies inherent in the system. Unfortunately, high capital investment in the solid waste management sector does not necessarily lead to improvements in the quality of service in many developing countries [22].

The economic impact of poor waste management is often not considered in planning decisions. For health issues, costs can be associated with days lost from work, the costs of medical treatment and even loss of life. Although this analysis has not been done for Ethiopia [8], it is likely to result in losses of millions of birr a year. In addition, an outbreak of a serious disease like cholera could cost millions in lost commercial earnings. On the environmental side, the costs can be less primary productivity on land or sea due to pollution, loss of value of property near pollution, loss of environmental services if important habitats are degraded, loss of commercial earnings and the cost of cleanup. The reduction in quality of natural assets and aesthetic value because of pollution from waste can lead to economic costs

\section{Methodology}

\subsection{Description of Study Area}

LagaTafoLagaDadi town administration is located in Oromia National Regional State, along the avenue to DessieMekele at a distance of $21 \mathrm{~km}$ from Addis Ababa. The town surrounded by Berek woreda of special zone surrounding Finfinnee in all directions except in South West which surrounds Addis Ababa. Its astronomical location is between $9^{\circ} 01^{\prime} 29^{\prime \prime} \mathrm{N}-9^{\circ} 06^{\prime} 0^{\prime \prime}$ North Latitude and between $38^{\circ} 53^{\prime} 42^{\prime \prime}$ E - $38^{\circ} 55^{\prime} 30^{\prime \prime}$ East Longitude. It is located at altitude 2,316 to 2,500 masl. The mean annual, maximum, and minimum temperatures of the town are calculated to $17.22^{\circ} \mathrm{C}, 23.76^{\circ} \mathrm{C}$ \& $10.67^{\circ} \mathrm{C}$, respectively, which is the characteristic of a warm temperate climate [14]. Recently the town administration has four kebeles namely, LagaTafo (01) and LagaDadi (02), Dambel and Eka Sadden with in an area of 24,350 hectares. According Oromia Urban Planning Institute, 2016, the town had a population of 52054 .

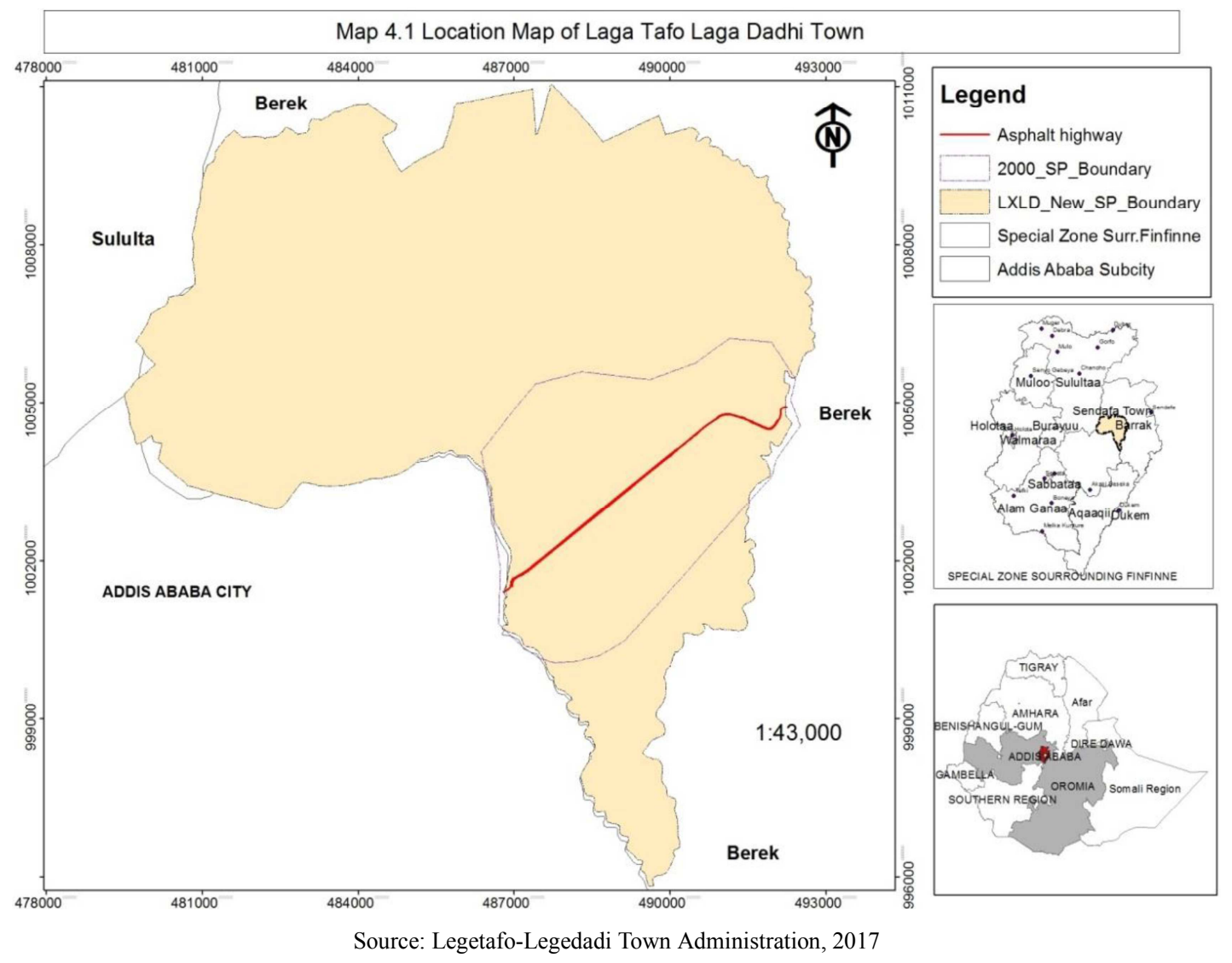

Figure 2. Location Map of Laga Tafolaga Dadi town.

\subsection{Research Approach}

The research applied both quantitative and qualitative research approaches. These help the use of a broad spectrum of quantitative and qualitative approaches in order to gather and analyze data. 


\subsection{Research Design}

The research employed descriptive survey research design that helps to describe phenomena accurately not only using quantitative data but also qualitative data. This design also corresponds to what Bryman describes as Cross-sectional research design that aims at getting data from multiple cases at a given point in time to analyze relationships across a number of variables of interest [4].

\subsection{Data Sources and Types}

The data sources for the research were from both primary and secondary sources. The primary data was collected from households, key informants, focus group participants, and concerned government officials at different levels. The data were supported by the direct observation of the researcher to the study sites. In utilizing secondary sources, published articles, research works, previous studies, books, government reports from the federal and regional offices, municipal administration offices, and Central Statistical Agency and other sources were reviewed. In addition to this, both qualitative and quantitative data have been collected through data collection instruments used for the research.

\subsection{Data Collection Tools}

To collect data, the study used key informant interview, document review, observation, and Focus Group Discussions questionnaire and non-participatory observations. Depending on the kind of data, the researcher used the most appropriate data collection method to get the data from the different respondents.

\subsubsection{Document Reviews}

Documents obtained from the municipality regarding solid waste management were reviewed. The basic points identified from the reviews were used as inputs to consolidate the findings of the study.

\subsubsection{Interviews}

Key informant interviews were conducted among four coordinators and four experts from solid waste management in the municipality and Kebele levels. The main instrument used to interview key informants was a semi-structured interview, which contained open-ended questions.

\subsubsection{Focus Group Discussions}

To use the social dynamics of the group and to collect essential information about their opinions, experience, perception, beliefs, and attitude on solid waste management two focus group discussions, each of which consisting of 915 members, were purposively selected from households from all four Kebeles by taking into account sexes, various ranges of age, and occupations.

\subsection{Sampling}

\subsubsection{Sample Size Determination}

The sample size determination process was conducted using two sample size determination formulas. The study also considered households living in the city as the primary source of information for the survey research. Therefore, the population frame is 10411 households who have been living in the city. In determining the representative sample size for the study, the researcher has used two category of sampling formulas.

The first formula, which is used in the study, is the one proposed by Krejcie and Morgan [10] for determining needed sample size in research when the population is known. The formula is stated as:

$$
S=\frac{X^{2} N P(1-P)}{D^{2}(N-1)+X^{2} P(1-p)}
$$

Where: $\mathrm{S}=$ required sample size; $\mathrm{X}^{2}=$ the table value of chi-square for 1 degree of freedom at 0.05 confidence level (3.841); $\mathrm{N}=$ the population size; $\mathrm{P}=$ the population proportion (assumed to be 0.50 as this would provide the maximum sample size); and $\mathrm{d}=$ the degree of accuracy expressed as a proportion (.05).

Accordingly, using the above sampling formula, around 368 households are selected as the representative of the population. However, as there is a need to manage the sample size is representative of the population, additional sampling formulas is required to be applied in the study. Accordingly, the second formula considered in the study is the one proposed by Cochran (1977) as a finite population correction to determine the final sample that turns out to be $5 \%$ or more of the total population. The formula can be stated as:

$$
n 1=\frac{s}{1+\frac{S}{N}}
$$

Where: $\mathrm{S}=$ is desired sample size; $\mathrm{n} 1=$ is the new value for the sample size adjusted using Cochran's population correction formula; $\mathrm{N}=$ is the total number of the population from which ' $n$ ' is being drawn.

In this case, applying, the formula around 348 households selected as sample that turns out to be $5 \%$ or more of the total population. Finally, the following formula used to adjust the sample size for non-response rate.

$$
\text { Final sample size }=\frac{\text { Effective sample }}{1-\text { non-response rate anticipated }}=\frac{348}{1-10 \%}=384
$$

Accordingly, using the formula considered appropriate for this study, around 384 respondents drawn proportionally for both residential households and non-residential entities of Kebeles of the city. In addition, $35 \mathrm{CC}, 5$ government institutions, and 5 health facilities (health center and clinics) samples were investigated. Such limited samples used due to financial, time and effort constraints [6].

\subsubsection{Sampling Procedure}

The four kebeles of city administration were totally sampled using purposive techniques. This helps the researcher to assess the opinion of residents living in different kebeles, having varies demographic characteristics 
like occupation, income, \&etc. and also to consider the local, community neighborhood, and other organizational structure solid waste management. The procedure of reaching the individual respondents or households selected for sampling based on convenience sampling technique. It was not deemed viable to choose the sample by random sampling, because the City administration did not have population and households' database or list of all the residents, traders, and market venders. Hence, the researcher had selected four influential residents with additional four expertise of the city administration to fill questionnaire through convenience sampling method.

\subsubsection{Ethical Considerations}

The researchers strictly followed all ethical rules and regulations of academic research at all stages of this study. In all their dealings with participants, the investigators maintained a principle-based and professional relationship with all respondents ensuring that their willing consent is secured before requests for information were extended to them and respecting their dignity.

The participants of the study were told exactly what the research was about and why the researchers are conducting the study and told in clear and unambiguous terms that participation was totally voluntary. Keeping the confidentiality of the information obtained, maintaining the privacy and anonymity of respondents, and ensuring the presence of a healthy dose of skepticism on all information obtained were the hallmark of this study. No information that could potentially harm the participants, during or in the aftermath of the study, were disclosed to anyone.

The study did not cause, intentionally or otherwise, any harm to the respondents as well as those who provided access to secondary documents. Nor did it impose serious burden on the participants. The participants were all responsible adults and none faced any pressure to take part in the study. Moreover, given his knowledge of the two languages used as medium of communication in the Town, Amharic, and Afaan Oromo, the researchers faced no communication barrier when interacting with the participants in the study. This enabled the researchers to speak with clarity and precision and to hear and understand all the verbal and nonverbal communication of the participants of the study without any glitch.

Throughout the study the researchers showed respect for the different cultures in the Town and there was no occasion for favoritism whatsoever. During the field observations, the researchers made sure that disruptions to the participants were kept to the minimum as much as possible.

Since the study was self-funded by the researchers, there was no financial interest in the study nor any conflict of interest involved since the researchers are motivated by any interest other than the interest of advancing knowledge. The findings of the study were also reviewed objectively and without any bias.

\section{Results and Discussion}

\subsection{Challenges of Solid Waste around Open Dumpsite}

The absence of a properly engineered disposal site is one of the main agents causing environmental pollution and threats to public health in Legetafo-Legedadi town. Accordingly, 59 percent (216) of the respondents stated that open dumpsite posed public health risks; 18.9 percent (69) said that there was uncontrolled dumping even at the dumpsite, and 12.3 percent (45) argued that the open dumpsite contaminated groundwater (Table 1).

The main problem that the community is facing with respect to the open dumpsite is health-related. During the focus group discussion, experts and heads of different sectors with the municipality expressed that those around the open dumpsite are facing acute upper respiratory infections and fever and a host of illnesses such as typhoid and diarrhea. Improving environmental conditions in cities and towns helps in reducing poverty directly as well as indirectly. The open dumpsite is not only a nuisance. It is not only a health hazard. Such unprotected and open dump sites put the health of residents in jeopardy as it is conducive for the breeding mosquitoes, rats, flies, and other vectors of infectious diseases [16]. It is an environmental danger as well.

In many cities, as is the case in Legetafo-Legedadi, the poor do not have access to formal solid waste collection services and live in unsafe, marginal, and environmentally hazardous areas such as polluted land-sites near the solid waste dump sites. These conditions lead to poor environmental health, which aggravates poverty and leads to impacts such as loss of income due to sickness and disease, inadequate medical treatment, and increased spending on healthcare which depletes household savings [9].

The municipality's poor handling and monitoring of the dumpsite encourages the poor to make a living out of the tragedy. Modak (2016) argued that informal solid waste collectors, often operating without any protective equipment, are exposed to a wide range of health risks such as HIV, tetanus, respiratory problems, neural damage, injuries, premature drinking, stress, skin, and gastric problems. Similarly, while the exposure of communities closer to the dumpsites is higher, there are broader public risks associated with air pollution as well. [15]

The poor service could also prompt households to resort to open-air burning of the waste they generate and those they stumble into in their neighborhoods. The inefficient local open-air burning of wastes could in turn produce air pollution. Let alone the spontaneous combustion of refuse at dumps, household levels or neighborhood levels, the incineration of waste can create pollution at plants if the latter lack effective treatment facilities [3].

A study in southeastern Turkey by Bernstein (2004) indicates that there may be a close relationship between proximity to dumpsites and community health, particularly for the poor. Residents routinely faced a lot of diseases and illnesses because they have to live close to the landfill. "Children are playing with syringes and bottles. They are 
dirty. Children are sick, and there is no doctor." Residents of communities also added: "The wind spreads plastic bags from the landfill. Our cattle are ill because they eat these plastic bags." [3].

The leachate from the dumpsite pollutes underground water, which is an important alternative water source for the residents and also loose papers and plastics blown by wind result in an aesthetic intrusion of the surrounding environment. A study conducted by [13] also noted that poor and improper solid waste management at Legetafo-Legedadi imposed adverse effects on the community's economic wellbeing and health, not to mention the residents' loss of the aesthetic values of the environment.

Table 1. The major problems encountered on the dumping sites.

\begin{tabular}{llll}
\hline What do you consider the most urgent problem related to the present dumping site? & & \\
\hline & Frequency & Percent & Valid Percent \\
\hline public health risk & 216 & 59.0 & 61.4 \\
groundwater contamination & 45 & 12.3 & 12.8 \\
it becomes an eyesore with unpleasant odors & 9 & 2.5 & 2.6 \\
uncontrolled dumping at the area & 69 & 18.9 & 19.6 \\
nothing is wrong with the dump site & 13 & 3.6 & 3.7 \\
Total & 352 & 96.2 & 100.0 \\
Missing System & 14 & 3.8 & 76.7 \\
Total & 366 & 100.0 & 100.0 \\
\hline
\end{tabular}

Source: Survey data, 2019

\subsection{Environmental Impact}

Leaks from the waste may contaminate soils and water streams, and produce air pollution through emissions of e.g. heavy metals and persistent organic pollutants (POPs), ultimately creating health hazards. Other nuisances caused by uncontrolled or mismanaged waste disposal, which may affect citizens negatively, include impacts at local level, such as landscape deterioration, local water and air pollution, as well as littering [20].

According to focal group discussion and field observation, today Legetafo-Legedadi town is faced with poor solid waste management with the attendant short-term and long-term environmental problems. One of the main problems facing the Town is open and indiscriminate dumping of refuse. Moreover, piles of decaying garbage are found in strategic locations in the heart of the town. Leachates from refuse dumps are most certainly percolating into the soil and contaminating both underground and fresh water sources. Moreover, the Town's open landfill is located on the top slope of Legetafo River. Run off from the landfill can easily pollute the river, especially during the rainy season.

Adding salt to the injury, scavengers and stray animals invade the roadside garbage and litter the waste over large areas causing much aesthetic damage to the atmosphere. In addition, the organic solid waste emits obnoxious odor upon decomposition. In addition, waste products like plastic and rubber easily pollute he atmosphere with noxious fumes. The fact is that due to the poor management of solid waste management, we can find solid waste in every corner of the Town becoming a source of air and water pollution, land contamination, and environmental degradation.

\subsection{Economic Impact}

The classical economic mechanism of supply and demand controlling the flow of goods and services does appear to fail when it comes to waste materials. Consequently, to protect the natural environment, government and society need to take appropriate measure. Among the proper measures to control waste are regulations prohibiting the uncontrolled disposal of waste and prescribing minimum standards for treatment and deposit. Controlled disposal or recycling involves costs, i.e. waste materials are assigned a negative economic value in the form of a disposal fee. In exchange for the disposal fee, the economic value "absence of pollution" is created [12].

The central economic problem is allocating the costs for a clean environment to all the stakeholders. Waste management used to be the responsibility of the public domain and financed by taxpayers, with little or no incentive for the consumer to reduce the rate of waste production. In order to incentivize waste reduction, the "polluter pays" principle has been introduced and increasingly used in many countries [12].

In high-income countries, operating costs for integrated waste management, including collection, transport, treatment, and disposal, generally exceed $\$ 100$ per ton. Lower-income countries spend less on waste operations in absolute terms, with costs of about $\$ 35$ per ton and sometimes higher, but these countries experience much more difficulty in recovering costs [9].

From field observation in Legetafo-Legedadi, there was evidence that the Town still loses a significant amount of potentially valuable recourses and "secondary raw materials" such as metals, wood, glass, paper, and plastics which can be recycled or reused. Even though each household in the Town currently generates on average $156.95 \mathrm{~kg}$ of waste every year [14], only $5 \%$ of this waste is reused or recycled, while waste can make a big contribution to economic growth and job creation. A study published by the EC in 2012 showed that full implementation of EU waste legislation saves $€ 72$ billion a year. The same study noted that the EU recycling sector valued at $€ 42$ billion and creates over 400, 000 jobs by 2020 . However, even in the EU, illegal waste operations are causing missed opportunities for economic growth, a finding backed up by several case studies (BIO Intelligence Service, 2011; EC, 2012). Clearly, informal waste management 
activities can provide income and support the livelihoods of the poor and marginalized, but the price in terms of direct health impact for those involved is likely to be very high [21]. Unfortunately, Legetafo-Legedadi is experiencing not only lost opportunities for economic gain but also harvesting the ill-effects of poor solid waste management.

\subsection{Health Impact}

That improper waste management can have negative impacts on both the environment and public health is well known. Negative impacts can be due to different handling and disposal activities resulting in health problems. Inadequately disposed or untreated waste may cause serious health problems for populations surrounding the area of disposal or elsewhere. Uncontrolled or mismanaged waste disposal practices are known to cause various diseases such as bacillary dysentery, diarrhea and amoebic dysentery, plague, salmonellosis, trichinosis, endemic typhus, cholera, jaundice, hepatitis, gastro enteric diseases etc [21].

In urban low-income neighborhoods such as LegetafoLegedadi, up to two-thirds of solid waste is not collected [2]. In areas with poor service coverage such as LegetafoLegedadi, the incidence of diarrhea can be twice as high and acute respiratory infections can be six times higher than in areas with frequent waste collection [20]. Waste is often dumped or burned, releasing toxic airborne chemicals and liquid runoff that contaminates vital water sources [1]. And the Legetafo-Legedadi region is a vital water source.
During the focus group discussions with Health professionals and experts of the Town, they openly admit that improper management of solid waste could be causes for complication of health problems. They do understand that vectors like rats and insects invade refuse dumps and breed potentially spreading various diseases in the Town. For instance, rats dwelling in the dumpsite could consume infectious solid wastes potentially spreading diseases like plague, salmonellosis, trichinosis, and endemic typhus. In addition to this, Water and food contamination through flies causes various diseases in humans as dysentery, diarrhea, and amoebic dysentery. The greatest danger is to the water supply, which if contaminated with pathogens present in solid wastes, may result in cholera, jaundice, hepatitis, and gastro enteric diseases.

The choking of drains and gully pits by the solid wastes, which were evident during the field visits, has resulted in water logging, which facilitates the breeding of mosquitoes enhancing the probability of diseases like malaria. Even if Legetafo-Legedadi is unknown as a malaria-prone region, it is difficult to be complacent in the age of disruptions and anomalies caused by climate change. Moreover, unsafe handling medical wastes could become conduits for disease transmission. The risk of body injury could not be ruled out due to the improper handling of sharp materials, which in turn could cause transmittable diseases like HIV/ADIS. The dismal health statistics compiled by the municipality as shown in Table 2 below cannot be unrelated to poor management of solid wastes.

Table 2. The prevalence of diseases caused by poor management of solid wastes.

\begin{tabular}{llll}
\hline $\begin{array}{l}\text { Types of disease } \\
\text { Related to SW }\end{array}$ & $\begin{array}{l}\text { From 41823 Total Case which } \\
\text { treated in HCs in 2017 }\end{array}$ & $\begin{array}{l}\text { From 32301 Total Case which } \\
\text { treated in HCs in 2018 }\end{array}$ & $\begin{array}{l}\text { From 40672 Total Case which } \\
\text { treated in HCs in 2019 }\end{array}$ \\
\hline AURTI & 8112 & 5675 & 5335 \\
Typhoid Fever & 221 & 956 & 651 \\
Diarrhea & 5868 & 2144 & 1545 \\
Pneumonias & 166 & 293 & 81 \\
Total & $7067(16.9 \%)$ & $9050(28 \%)$ & $6222(15.2)$ \\
\hline
\end{tabular}

Source: Laga Tafo Laga Dadi Health Office, 2019

\section{Conclusion and Recommendation}

\subsection{Conclusion}

1. Failure of proper management of solid waste causing environmental pollution and threats to public health in Legetafo-Legedadi town. According to survey of the study, 59 percent (216) of the respondents stated that open dumpsite posed public health risks; 18.9 percent (69) said that there was uncontrolled dumping even at the dumpsite, and 12.3 percent (45) argued that the open dumpsite contaminated groundwater.

2. During the Focus Group Discussion, experts and heads of different sectors with the municipality expressed that uncontrolled open dump site causes for health risk in the town those who live around the open dumpsite are facing acute upper respiratory infections and fever and a host of illnesses such as typhoid and diarrhea.
3. The data from Health office of the Town shows that from those who came to health centers for treatment the prevalence rate of diseases caused pertinent to poor solid waste management were, in 2017 (16.9\%), in 2018 $(28 \%)$ and in $2019(15.2 \%)$

4. The poor management of solid waste has impact on economy. The Town of legetafo-Legedadi still loses a significant amount of potentially valuable recourses and "secondary raw materials" such as metals, wood, glass, paper, and plastics which can be recycled or reused. Even though each household in the Town currently generates on average $156.95 \mathrm{~kg}$ of waste every year [14], only $5 \%$ of this waste is reused or recycled.

\subsection{Recommendation}

1. To curtail the critical problems and the impact of poor solid waste management in Legetafo-Legedadi the 
researchers recommend an integrated solid waste management system which is holistic and comprehensive system of waste management which enable the town to uses a range of inter-related collection and treatment options.

2. The town administration should follow inclusivity such as involvement of all stakeholders, governmental or non-governmental organs, the formal or informal sectors, for profit or nonprofit schemes, and take into account interactions between the waste management system and other urban systems. In other word, accommodating the aspirations of all stakeholders; from waste generators to waste management and service providers and encouraging local ownership and responsibilities/participation through a consultative approach.

3. The Town Administration should deal with all types of waste materials, as opposed to focusing on specific materials which means give due attention to sources of municipal solid waste and includes such steps as waste collection and sorting followed by one or more of recycling, composting, landfill or at least controlled dumpsite.

4. The Town Administration should be integrating different response functions such as legal, technical, managerial, financial and policy

\section{References}

[1] Akinbile, C. O., \& Mohd, S. Y. (2011). Environmental Impact of Leachate Pollution on Groundwater Supplies in Akure, Nigeria. International Journal of Environmental Science and Development 2 (1): http://www.ijesd.org/papers/101F10106.pdf, 81-86.

[2] Baker, J. (2012). Climate Change, Disaster Risk, and the Urban Poor: Cities Building Resilience for a Changing World. Washington, DC: World Bank. World Bank.

[3] Bernstein, J. (2004). Toolkit for Social Assessement and Public Participation in Municipal Solid Waste Management. Washington D. C: Urban Environment Thematic Group, ECSSD.

[4] Bryman, A. (2004). Social Research Methods. Oxford: Oxford University Press.

[5] Blore, I, \& Nuan, F. (1996). Living with Waste: Public Valuation of Solid Waste Impacts in Bangkok II, Papers in the Administration of Development, 57, Development Administration Group, University of Birmingham.

[6] Cohen, L., Manion, L. and Morrison, K.. (2000). Research Methods in Education,. London: Routledge.

[7] Fraenkel, J. \&Wallen, N. E. (2009). How to design and evaluate research in education $\left(7^{\text {th }}\right.$ ed). Boston, MA: McGraw-Hill.

[8] Hailu, W. (2011). National Waste Management Strategy for Ethiopia, Ministry of Urban Development and Construction. Addis Ababa, Ethiopia.
[9] Kaza, S. L.-T. (2018). What a Waste 2.0: A Global Snapshot of Solid Waste Management to 2050. Washington, DC: World Bank Group: World Development Series.

[10] Krejcie, R. V., \& Morgan, D. W. (1970). Determining Sample Size for Research Activities. Educational and Psychological Measurement, 30, 607-610 Ethiopia. Journal of Environmental Science and Technology, 7, 107-122.

[11] Leedy and Jeanne Ellis Ormrod (2005). Practical Research: Planning and Design, Ninth Edition, Merrill. Pearson Education, Inc.

[12] Ludwig, A., Parada, C., Loreto, E. L. S., Goñi, B. (2003). Genetics and molecular analysis of a Drosophila willistoni spontaneous mutation similar to eyeless. D. I. S. 86: 138-142.

[13] Mesfin Assefa, Birhanu Girma, Community Participation in Integrated Solid Waste Management in Legetafo-Legedadi Town, Oromia, Ethiopia, Urban and Regional Planning. Vol. 5, No. 1, 2020, pp. 15-24. doi: 10.11648/j.urp.20200501.13.

[14] Mesfin Assefa, Muktar Mohammed. Solid Waste Generation Rate and Characterization Study for Laga Tafo LagaDadi Town, Oromia, Ethiopia. International Journal of Environmental Protection and Policy. Vol. 5, No. 6, 2017, pp. 84-93. doi: 10.11648/j.ijepp.20170506.11.

[15] Modak, P. (2016). Municipal Solid Waste Management: A Guide for Sustainable Urban Development in the 21st Century. Shanghai.

[16] Sinthumule, N. I., \& Mkumbuzi, S. H. (2019). Participation in Community-Based Solid Waste Management in Nkulumane Suburb, Bulawayo, Zimbabwe. Resources, MDPI, 1-16.

[17] UNEP 2005. One Planet, Many People: Atlas of Our Changing Environment. Nairobi, Kenya: United Nations Environment Programme, Division of Early Warning and Assessment. Earth Print.

[18] UNEP. (2009). Developing Integrated Solid Waste Management Plan-Training Manual', Vol. 3: Targets and Issues of Concern for ISWM. UNEP.

[19] UN-HABITAT. (2009). Solid Waste Management in the World's Cities. Nairobi, Kenya: UN-HABITAT.

[20] UN-Habitat. (2010). Solid Waste Management in the World's Cities: Water and Sanitation in the World's Cities 2010. Earths can. http://www.waste.nl/sites/waste.nl/files/product/files/swm_ $i$ world_cities_2010.pdf. London and Washington, DC: UNHabitat.

[21] WHO. https://www.who.int/gho/publications/world health_statistics/ 2016/en/

[22] Woldetsadik, A. A. (2017). Practices of solid waste management by municipality and community in Oromia Regional State of Ethiopia: A case of Adama City, Ethiopia. SSRG International Journal of Agriculture \& Environmental Science 4 (1), 1-7.

[23] World Bank. (2012). A Global Review of Solid Waste Management: Urban Development Series Knowledge Paper No-15. World Bank. 